\title{
Challenges for the sustainability of university-run biobanks
}

Kongsholm, Nana Cecilie Halmsted; Christensen, Søren Tvorup; Herrmann, Janne Rothmar; Larsen, Lars Allan; Minssen, Timo; Pedersen, Lotte Bang; Rajam, Neethu; Tommerup, Niels; Tupasela, Aaro Mikael; Schovsbo, Jens Hemmingsen

Published in:

Biopreservation and Biobanking

DOI:

10.1089/bio.2018.0054

Publication date:

2018

Document version

Peer reviewed version

Citation for published version (APA):

Kongsholm, N. C. H., Christensen, S. T., Herrmann, J. R., Larsen, L. A., Minssen, T., Pedersen, L. B., Rajam, N., Tommerup, N., Tupasela, A. M., \& Schovsbo, J. H. (2018). Challenges for the sustainability of university-run biobanks. Biopreservation and Biobanking, 16(4), 312-321. https://doi.org/10.1089/bio.2018.0054 


\title{
Challenges for the sustainability of university-run
}

\section{biobanks}

\begin{abstract}
Most university biobanks begin like other university research projects, i.e. with an idea conceived by an individual researcher in pursuit of his/her own research interests, publications, funding and career. Some biobanks, however, come to have scientific value that goes beyond the projects that were initially responsible for the collection of the samples and data they contain. Such value may derive from inter alia the uniqueness of the samples in terms of their sheer volume, the quality of the samples, the ability to link the samples with information retrieved in disease registries, or the fact that the samples represent very rare diseases. This paper focuses on biobanks of this kind, and the special obligations that publicly funded universities have to ensure the sustainability of biobanks with continued scientific value. We argue that universities should adopt policies to deal with the various, diverse issues which may arise during the lifecycle of a biobank. The policies should be flexible, accommodate the freedoms of individual researchers, and reflect the multifaceted nature of biobanks. Yet they should be specific enough to provide guidance and robust enough to safeguard legal norms and ethical values. The paper sets out concrete recommendations which universities should consider and act upon.
\end{abstract}

Keywords: biobanks, sustainability, property rights, access to samples, custodianship, FAIR principles 


\section{Introduction}

Universities play an important role in the production of knowledge through scientific research ${ }^{1,2}$. In this knowledge production process, universities become sites where, data, as well as physical materials, are collected and stored over time. Traditionally, universities have sought prestige by developing their library collections ${ }^{3}$ or investing in the technical equipment made available to research groups. Institutional repositories have also become an important resource that universities develop to collect and organize the collective output of their staff. ${ }^{4}$ Furthermore, a number of international initiatives have launched policies to encourage the systematic collection and archiving of data collected using public funding. ${ }^{5,6}$ Finally, many countries have established repositories or archives for accumulated data. Examples include The UK Data Archive (http://www.data-archive.ac.uk/) and The Finnish Social Science Data Archive (http://www.fsd.uta.fi/en/).

Another valuable university resource is the biobank. Biobanks play an important role in the development of biomedical research, and the large collections of samples of human tissue and data held in them are often described as a kind of Eldorado or goldmine waiting to be discovered and used for medical breakthroughs to the benefit of mankind. ${ }^{7,8}$ Although there is a large variety of different types of biobank, many are located in publicly funded universities and are run wholly or in part by university staff, and there appears to be little consensus or standards on how to manage these collections in the long run. Biobanks are also becoming important nodes around which international research collaboration is arranged, often with countries or regions with vastly different legal and ethical frameworks for protecting donor rights. ${ }^{9}$ Although during the past two decades there has been a great deal of research on the governance of biobanks, ${ }^{10,11}$ universities, as institutions of higher learning, have shown surprisingly little interest in the development of national or international standards and guidelines for their longterm sustainability. Chalmers et al. (2016) ${ }^{12}$ have suggested that the lack of attention to the sustainability of biobanks may prove to be their biggest challenge yet. 
Governance of biobanks involves structurization of the processes and relationships involved in the pursuit of the goals defined by biobanking institutions. ${ }^{13}$ It may also reflect the exercise of authority by state actors to steadily and effectively manage the development of biobanks. This management is often achieved through practices, principles, regulations and other guidelines. Governance may thus involve self-regulation as well as legal parameters. ${ }^{14}$ The growth of the biobanks which have evolved from university-based sample collections within most universities begins like other university research projects, i.e. with an idea conceived by an individual researcher or research group in pursuit of their own research interests, publications, funding and careers. Over time, successful biobanks take on a life of their own, however, and expand beyond the original idea and plans. Collections grow as new funding is secured, and as international research ties are established leading to samples and data being exchanged across borders. New researchers join the project, and others leave (sometimes with 'their' samples in the back of the car or 'their' data on a memory stick). Such developments mean that serious consideration must be given to university-based governance of the establishment, maintenance and protection of biobanks.

The buildup of biobanks in incremental steps without central coordination poses a number of challenges for universities. University administration is normally involved only if necessary, and so far most universities have probably been happy not to be bothered with additional tasks. For these reasons, many universities lack systematic and coherent policies on biobanking and find themselves "accidental biobankers". However, universities in which biobank collections are maintained must accept and shoulder the practical, legal and ethical responsibilities associated with biobanking. Practically, the necessary infrastructure, including funding, must be provided; legally, rules regarding the collection and sharing of samples and data must be observed; and ethical obligations pertaining to research must be respected. Universities attend to all of these with a view of furthering the immediate interests of their employees (and thus themselves). Decisions to expand or close biobanks are made by the researchers involved, and within the scope of possibilities defined by their funding and research interests. 
Universities also have an ethical responsibility to ensure that resources maintained on their premises are used to their full potential. Non-use or underuse of important collections, or the slow destruction of collections due to negligence, amounts to a waste of resources that have been collected using public funding. ${ }^{15,16}$

Some biobanks are connected with issues, values or interests which go beyond the individual and short-term interests of the researcher, research project or university they are associated with. We argue that where such biobanks are concerned universities should recognize that they have a responsibility which goes beyond those following from their own, immediate interests and reflects general societal interests. Unique (one-of-a-kind) biobanks will often fall into this category, since their destruction could gravely harm future research. A case in point is the Copenhagen Family Bank (CFB), which contains DNA and phenotypic/clinical data from >900 large families [http://www.genomedenmark.dk/english/ethics/patientmaterials/]. CFB has been used to map numerous genetic loci, from cystic fibrosis $(\mathrm{CF})^{17,18,19}$ to blue eyes, ${ }^{20}$ and it has lately formed the basis for a Danish reference genome project. ${ }^{21}$ For this and similar biobanks, societal interest in preserving the data goes far beyond the shortterm interests of its present keepers. Other biobanks may merit special attention because of legislative or contractual restrictions which, for example, limit access, or use, and which have to be respected also by future generations of users of the biobank.

The long-term use of samples for secondary purposes may also involve significant ethical, legal, and financial implications for universities. Arizona State University, for example, agreed to pay 41 members of the Havasupai Tribe 700000 USD for improper use of their blood samples in genetic research. ${ }^{22}$ The samples had originally been collected in 1990 for a study on diabetes, but had been shared and used in multiple studies of other conditions as well. In such instances, simply 'remembering' the special background and conditions in which the samples were collected is imperative. Similar entitlement debates are not uncommon in relation to biobanks, and the samples 
contained within them, ${ }^{23}$ but universities appear to lack a common framework for working through many of the ethical, social and legal issues associated with long-term storage of tissue samples.

In the present paper we aim to address some of these shortcomings by offering some recommendations on the sustainability of university-based biobanks.

\section{Methods and Materials}

This paper is based on insights from the interdisciplinary research project Global Genes, Local Concerns (GGLC) (http://globalgenes.ku.dk). The project ran from 2013 to the end of 2016 and was funded by the University of Copenhagen. GGLC sought to combine legal, ethical, social and scientific perspectives on cross-national biobanking and translational exploitation. Working in several work packages, the natural sciences group (genetics and biology) sought first to identify candidate genes in patients with chromosomal translocations and/or rare diseases, such as microcephaly and congenital heart disease in several countries (Denmark, Finland, Pakistan, the USA). The candidate genes were then subjected to functional analysis in tissue cultures or model organisms to study their role in specific cellular processes and/or the development of relevant organs such as the heart and brain.

The legal, ethical and social components of the project sought to monitor this research process to better understand what ethical, legal and social challenges and questions arose about the collection of samples from international partners and their subsequent analysis in Denmark. Concentrating on biobanking in a university setting, the project aimed to study, and ultimately provide guidelines to overcome regulatory barriers to, biobank research and the utilization of research results, while at the same time securing the ethical legitimacy of the research and safeguarding societal interests in access to information and innovation.

This paper is a synthesis of the overall findings on university-based biobanks and presents some of the shortcomings that we have observed during the course of the research project. We base our findings on the 
following data: qualitative, semi-structured interviews with geneticists and biologists in Denmark, Pakistan and Finland; fieldwork ${ }^{24}$ in several countries, including Denmark, Pakistan and Finland; interviews with patients in Pakistan ${ }^{25}$ and Denmark; ${ }^{26}$ and policy documents, as well as legal text analyses in Denmark. Research was also conducted on aspects of commercialization with publicly funded biobanks in Estonia, Austria, Finland, and Luxembourg. ${ }^{27}$ These studies included university-linked biobanks and technology transfer office employees as an object of study.

In addition, we have held several workshops with project members to discuss issues related to the collection of human tissue samples and the challenges raised by the long-term sustainability of these collections within universities. One theme that often arose in discussions was that most universities lack systematic methods for tracking and evaluating the various collections that are maintained within their facilities. As a result, we have sought to develop some general guidelines that could help university administrators evaluate and de velop more systematic methods in managing the tissue collections housed on their premises.

\section{Discussion: Biobanks and special obligations}

In the following sections we discuss the special challenges and opportunities for university-based biobanks, based on our data and results in the GGLC research project. We focus on two issues. First, biobanks may create special challenges for universities simply because they have been collected and are being managed by university staff and universities. Travelling under the 'university flag' no doubt opens doors to researchers which are closed to, for instance, researchers from industry. Universities should take action to make sure that biobanking practices do not undermine the high status of universities in society, but also to guarantee that values such as openness which are central to university research are respected in biobanking. Second, because biobanks often constitute an important 
scientific infrastructure, they need to be managed in ways which maintain their integrity and make them usable to outsiders. As indicated above, university biobanks are often not intended as biobank collections from the outset, but rather arise from ongoing research within the university. Hence, there is reason to assume that the collections are to some extent - perhaps, often implicitly - subject to the values, procedures and interests that guide not only university research at a higher level, but also interactions between researchers at a lower level.

\section{Biobanks and university research}

Universities generally enjoy a high degree of public trust, and with the exception of a few (highly publicized) cases of academic misconduct, citizens generally believe them to be trustworthy sources of new knowledge, technologies and innovation for the benefit of the population. This is largely a consequence of the universities' institutionalized observance of the basic principles of research integrity (such as honesty, accountability, responsibility, rigor, efficiency and objectivity). For example, Section 3 of the University of Copenhagen's rules on good scientific practice demand that research is conducted in a reliable manner; that primary data are kept secure and, as far as possible, made publicly available; that research results are presented openly and honestly; that there is openness regarding possible conflicts of interest; and that everybody who takes part in the research is credited in a fair manner. ${ }^{28} \mathrm{~A}$ major factor in preserving the public's trust is transparency about any research being conducted at the university - research largely undertaken by the individual researchers. To this end, universities place explicit demands on researchers to appropriately and adequately preserve their data, and to be willing to share them with other researchers so that results can be replicated. To take another example from the University of Copenhagen, its policy on research data states that "the individual researcher is responsible for choosing appropriate and adequate methods for collecting, storing and archiving research data. [...] As a general rule, it must be possible to recreate research findings", ${ }^{29}$ 
Transparency, as a fundamental principle of research integrity, is also observable in the wider scientific community - in many cases, willingness to share data is a prerequisite for publishing results in leading scientific journals. Thus the author submission guidelines for Nature state that "An inherent principle of publication is that others should be able to replicate and build upon the authors' published claims. A condition of publication in a Nature Research journal is that authors are required to make materials, data, code, and associated protocols promptly available to readers without undue qualifications" (http://www.nature.com/authors/policies/availability.html, accessed Dec 19 2017).

Few would deny that universities are the most important arena for basic research. Basic research aims to advance our fundamental knowledge of the world. It is a prerequisite of applied science and research - and thus of the development of new applications, technologies and therapies within and beyond the university setting. One example is the discovery in 1960 at University of Pennsylvania of a small chromosome, the Philadelphia $\left(\mathrm{Ph}^{1}\right)$ chromosome, in chronic myeloid leukemia (CML), a lethal hematological cancer. ${ }^{30} \mathrm{The}^{\mathrm{Ph}}{ }^{1}$ chromosome was later found to be a specific translocation between chromosomes 9 and $22^{31}$ which forms a fusion gene that encodes a new phosphorylating protein that drives CML. ${ }^{32}$ Subsequent screening for chemical compounds that block the phosphorylating activity of the fusion protein identified a compound ${ }^{33}$ that has revolutionized the treatment of CML. ${ }^{34}$ It can be seen, then, that basic research is a fundamental necessity in our society, underpinning such things as infrastructure and the health and well-being of citizens.

Basic research is largely driven by university researchers' curiosity about their field, not by the economic incentives that often characterize research in, for example, private pharmaceutical companies. It is often contended that for basic research to flourish and thrive - and in turn produce developments and technologies for the good of society through applied research - university researchers need, and should be granted, the academic freedom to focus on their particular research field without unnecessary regulations and demands. This follows from the right to academic freedom protected inter alia in the UNESCO Recommendation Concerning the Status of Higher- 
Education Teaching Personnel, which, in principle 29, emphasizes the right to "carry out research work without any interference, or any suppression, in accordance with their professional responsibility and subject to nationally and internationally recognized professional principles of intellectual rigor, scientific inquiry and research ethics". The value of academic freedom is often institutionalized in university rules. For example, the 'Academic Freedom at the University of Copenhagen' code states that academic freedom is crucial in that it "ensures that the University contributes to a free, prosperous society by creating, sharing and applying new knowledge in its own right. [...] $[\mathrm{UCPH}]$ protects freedom of speech and research and makes room for creative and professional development of all employees with respect for the entire university community and the University's overall objectives". ${ }^{35}$

This is no less important in the case of biobanks: to achieve the scientific development we want from university biobanks with respect to basic research, researchers should be allowed the freedom to focus on the basic research and not be subject to extensive regulations. This notion is instantiated by certain policies already regulating research. One example is the Danish Act on Research Ethics Review of Health Research Projects, which, in §10, mandates research ethics committees to give exemption in cases of registry-based research allowing researchers using register data to disregard the requirement of re-contact and informed consent provided that the research project does not pose health risks or other potential harms to donor(s).

As the above shows, transparency and the sharing of data and material are paramount in university research. Hence, guidelines and principles are in place to promote them. However, it seems that the practice of data sharing between institutions and researchers is guided not only by articulated principles, but also by unspoken and/or implicit values and rules in particular scientific communities. In our data, researchers reported that they share data not primarily because they are required to do so by a university code and wish to fulfil their responsibilities as university researchers, but also for reasons including: potential co-authorship; wanting to sustain your own reputation as someone who is willing to cooperate or "is a nice person"; potential future benefits such as being invited to conferences based on one's data; and/or being guided by the fact that one knows and likes the person asking for 
data or material, and wants to do them a favor. As such, data sharing is influenced significantly by the interpersonal relations and personal preferences of individual researchers, who appear to be guided by values such as trust, recognition and reputation. This indicates that a significant portion of research conduct lies outside the scope and reach of university guidelines and regulations. This has obvious impact on the practice of data sharing, which is of major significance in the field of university biobanking.

\section{Biobanks as an important research infrastructure}

As we suggested earlier, university-based biobanks are a special kind of biobank for a number of reasons. In relation to their long-term storage, it is necessary to determine whether they are worth keeping for periods of time extending beyond their original or intended use. Criteria that universities and research groups should consider in making such determinations need to be found. We suggest that a number of scientific criteria need to be considered. Scientifically these can be grouped into the three general categories of quality, quantity and uniqueness.

Freedman et al. $(2015)^{36}$ have suggested that a major challenge facing biomedical research using tissue samples is the lack of reproducibility of research results. ${ }^{37}$ There are numerous reasons for this problem, but the major cause is variable sample quality. In university-based biobanks this can be a serious problem, since in sample collections which have been amassed over careers spanning many decades the standards and norms associated with sample collection and storage will often have changed numerous times. In addition to these changes, university-based biobanks may adhere to more than one set of standards which are used in other fields of practice, such as in the clinic or by the pharmaceutical industry. Since university biobanks conduct basic research for the most part, their standards for collection and storage standards may also differ from those in commercial and clinical settings. This problem can become compounded over the decades. We argue that, as institutions of scientific knowledge production, universities have an interest in supporting the development of quality standards to be adhered by their employees, as well as in relation to the collections they maintain. In determining which tissue collections or 
biobanks are worthy of conservation or protection, it is therefore crucial to determine whether the samples can provide meaningful, as well as reproducible, information with scientific significance.

Another challenge to long-term use of tissue collections relates to the secondary use of samples collected many years ago. During the past few decades, informed consent practices have changed considerably. Researchers may see new value or research possibilities in collections which were originally collected with a particular research goal in mind. Within biobanking there are many cases pointing up the ethical and legal challenges associated with secondary use of important collections. ${ }^{38,39}$ Most universities lack policies for managing collections over long periods of time.

Many university-based tissue collection practices will end up being used in commercial ventures. There are many examples of "special" biobanks/repositories/collections for cell lines (ATCC) and plasmids (e.g. Addgene, RIKEN in Japan etc.), as well as model organisms, which successfully collect, maintain and distribute biological samples to research communities across the world. Many of these collections started on a small scale in a university research lab and are now either funded by external grants or run like a private company (e.g. Addgene). Although samples from humans are subjected to much stricter rules and regulations, universities are often unaware of the activities which may be going on within their walls.

We suggest that universities and university departments should, therefore, implement policies and practices which encourage the adoption of international standards and norms for collection and storage. This can be done by joining existing biobank networks which set standards and norms for biobanking: examples are TuBaFrost (http://www.tubafrost.org) for clinical pathology departments and biobankers and BBMRI-ERIC ${ }^{40}$ for national biobanking infrastructures. Encouraging implementation of existing and commonly shared standards and norms would also make existing collections of more interest to external collaborators, such as private industry, and make public-private collaboration more realistic. 
A number of other initiatives are underway within academia to support the reusability of existing data. The FAIR (Findable, Accessible, Interoperable, Reusable) Principles, for example, seek to make searches for existing resources easier by using machines, ${ }^{41}$ and a number of other standards, such as the Big Data 2 Knowledge (BD2K) initiative and the Joint Declaration of Data Citation Principles (JDDCP), seek to strengthen the emphasis on data as a reusable resource. In a similar vein, universities should become do more to encourage researchers to make their resources visible to the broader research community.

A more university-wide approach to sample quality is also important in relation to the reliability and quality of scientific research that the universities conduct, and it plays a major role in the reputation, as well as publication standards, that universities meet. Currently university researchers and research groups maintain their own sample collections in a wide variety of storage facilities which may exhibit a range of practices relating to the way the samples were procured and are now maintained. Universities may want to investigate whether it is a better idea to offer researchers and research groups centralized biobanking facilities to support their work.

The second important issue when evaluating whether university-based sample collections ought to be maintained beyond their original scope relates to biobank size. Biobank size does not necessarily refer to absolute numbers; it may be a matter of relative numbers. Some collections contain tens of thousands of samples from the general population, as is the case in cohort samples. Others include only dozens of samples, but they may nonetheless be important if the samples are from patients with very rare diseases. In this sense, a sample collection, though small in numbers, may represent all the collected samples that exist in the world and thus be a large collection in relative terms. Universities may wish to initiate discussions with their researchers in which questions about which collections are likely to be of great scientific value going beyond the original research collection purpose are tackled. 
The third group of collections which may be of broader interest are unique collections. These are generally collections with materials or samples that are not held anywhere else in the world. Alternatively, they may be collections that have been set up in such a way that permits the study of questions or phenomena in a way that is impossible with other collections. The notion of a unique collection can also be extended to collections that can be used in conjunction with other high-quality data sets, healthcare records, or registries. The Nordic countries, in particular, have unique collections in that the samples they contain can be compared with other sources of data using social security numbers. These numbers are unique personal identifiers which can be used to collect other health-related data on individuals. Collections that are unique in this way make up a broader network of data resources which many countries, particularly the Nordic countries, have sought, over the years to maintain and develop.

Universities can help to facilitate the professional collection and management of samples to ensure that the necessary quality standards are being met. Providing support for these activities will also help managers to determine which collections merit support for long-term sustainability and maintenance. The development of a common framework for maintaining collections which makes it unnecessary to apply for funding separately from numerous different sources could also help to support research groups.

\section{Long-term Sustainability of Biobanks}

Based on the foregoing analyses we suggest that the long-term sustainability of university run biobanks requires universities to accept and shoulder the responsibilities arising from their status as universities and to recognize that collectively biobanks are an important research infrastructure with an importance that often goes beyond the university where the collection has begun its life. 
It is very difficult to find ways to balance one's own short-term interests with broader and external interests. It is especially difficult if doing so imposes costs or requires one to identify values which are external - and therefore often unknown - to the immediate and recognizable interests of one's own institution. The problems here are familiar from 'homeless cohorts', for example. A recent example in Denmark was a rare collection of nearly 10000 brains collected between 1945 and 1982 which had been stored in the basement of Aarhus Psychiatric Hospital. A move to a newly built hospital triggered discussion of the continuing need to maintain the collection. The University of Aarhus, which held administrative responsibility of the collection on behalf of the Region (the regional authority responsible for the delivery of healthcare), found that the scientific value of the collection did not justify the cost. The collection had been forgotten for many years, and only one researcher had used the samples in recent times. The scientific value was contested as letters of support were sent from all over the world and commentators criticized the decision to destroy the collection as a short-sighted savings exercise rather than a scientifically founded decision; it was said that the limited previous research interest was due to the fact that the university had made no investments in maintaining the collection. ${ }^{42}$ A period was fixed to determine whether anyone was willing to take over the collection. Otherwise it would be destroyed (it has not been reported as yet whether attempts to find an adoptive researcher were successful). The Danish brain collection is just one example. Every day around the world collections are simply forgotten in basements and cryotanks because there is no institutional framework recording what samples exist as researchers retire, die or move to other employers. Consequently, in many cases there is no framework within which to determine which samples should be kept and maintained. Records of existing collections of samples and assessments of their continuing scientific value are prerequisites if other researchers are to be granted access to samples. Whether or not open access to samples can be considered a duty is considered below. 


\section{Open access to samples?}

Samples collected by university-employed researchers or within university-hosted projects will often be directly or indirectly financed by the taxpayer. University-operated biobanks may as a result be subject to the same demands of open access that has characterized research in recent decades. One argument for this relates to the democratization of knowledge, and the idea that open access to research archives and journals helps change the public presence of science and scholarship and increase the circulation of this particular form of knowledge for the benefit of society (which financed the research in the first place). Another argument refers to the fact that there is an increased emphasis on political accountability and a corresponding call for "evidence-based policymaking" in government. ${ }^{43}$ The argument is that public funding is increasingly framed as an investment that will provide evidence-based applied uses for the common good of society and as such should be openly accessible. It follows from this line of argumentation that biobanks that were funded by the public and consist of samples donated by citizens can become such an infrastructure. Consequently, universities should consider to what extent open access to samples and data should be considered a duty - either of a scientific, or ethical or legal sort. This section aims to provide a framework within which universities can attend to issues of open access when local biobanks collected by researchers take on an institutional infrastructure.

Biological samples in biobanks allow researchers from a variety of scientific backgrounds to ask questions about, for example, biological function and the relations between particular gene mutations and certain diseases. However, the ways in which the samples have been stored can influence not only what scientific answers researchers will obtain, but also the reproducibility of research results. Clearly, ensuring a certain level of quality of the samples is essential. Wilkinson et al. $(2016)^{44}$ define four principles of data sharing which have also been endorsed under the ERIC regime: data should be findable, accessible, interoperable and reusable (these are the FAIR principles mentioned earlier). Storage of samples then becomes vital in meeting the FAIR principles, in terms both of quality assurance and of the criteria by which the samples are searchable/accessible. There are no 
specific internationally agreed standards of quality on the preparation, storage and shipping of samples. However, inspiration for best practice can be drawn from repositories such as those mentioned above.

Universities should also consider if any access criteria should be applied to samples and data held in biobanks. The World Medical Association's Declaration of Helsinki, which outlines ethical principles that are applicable to research on identifiable human material and data, could serve as the basis for insisting that universities ascertain that the commissioning research project lives up to the following criteria: conforms to generally accepted scientific principles; is based on a thorough knowledge of the scientific literature or other relevant sources of information; and has adequate laboratory facilities. One solution here is for universities to set up Access Committees tasked with making scientific evaluations and decisions on criteria of access and access requests (as the UK Biobank has done).

As detailed above, access to samples and data collected by a researcher or a research project is in practice governed primarily by trust, personal relations, the fear of being scooped by others in the race to publish first, and a desire for status in the relevant scientific field. When universities become custodians of biobanks, ways to address these informal mechanisms of access could include consideration of whether any quid pro quo requirements of access would be appropriate, such as co-authorship or acknowledgement of the sample provider in the published article.

In assessing access to samples and/or data, universities must respect the rights and integrity of donors. A number of legal obligations flow from the protection of donors' integrity. First, in allowing access to samples and data, the biobank manager must assess whether informed consent from the donor is needed and whether permission from a Research Ethics Committee is needed. In this regard, the country of origin of samples will matter, since different origin countries will impose different legal demands, and samples originating from abroad will often require recontact with the original sample provider to ascertain if access requests from new research projects can be granted. Second, a number of duties relating to data protection must be checked. The recipient must have security protocols 
in place for the storage of samples or data and the recipient must not publish any material which could lead to the identification of individual donors.

Compliance with these obligations will become increasingly important and complex following the arrival of the General Data Protection Regulation (GDPR) (Regulation (EU) 2016/679), which will be binding in its entirety and directly applicable in all Member States from May 25, 2018.

The General Data Protection Regulation requires processing of personal data to be performed in accordance with principles of "lawfulness", "fairness" and "transparency". Under the new EU legislation, consent for data processing is not only the requirement; data must also be processed as per the standards set out in the regulation if it is to be lawful. Data subjects also have enhanced rights, including 'data rectification' (Art.16), which is the right to rectify any inaccuracy in relation to their personal data. Another important right offered to data subjects is the 'right to be forgotten' or a 'right of erasure'. This applies in cases where personal data are no longer necessary for the purposes of the research, or where they were not processed lawfully, or where the data subject withdraws consent (Art. 17). Researchers handling human data are thus bound by any request from a data subject to remove personal data collected by them. This duty does not arise, however, in certain cases, such as cases in which information is processed in public interest. Also, where data have been archived to be processed for scientific purposes in the public interest, the right of erasure may not be offered if it is "likely to impair the achievement of the objectives' of that processing" (Art. 89). This essentially means that institutional responsibility is enhanced considerably, and that the duties of universities and data controllers working within them are greater. Those managing university-linked biobanks need to consider consent requirements carefully and ensure that biobanks respect data minimization and overuse of consent. The new requirements set forth by GDPR, and their applicability to biobanks, will need to be carefully studied, and every university biobank should have proper compliance guidelines in place. ${ }^{45}$ 
Apart from personal data, it is essential to consider practices involving allied research data. Contemporary research in molecular biology involves a high level of interoperability of wet biology with computer technology. This has resulted in a "data mirage", meaning that it has become difficult to separate material (wet) data from other (dry) data secured through technical means. Against this background, university biobanks must evolve clearer practices for ownership and control of biological resources along with the data derived from such materials.

\section{Property rights}

Publicly funded biobanks are increasingly being treated as economic assets. They can be used to secure financial gains from research via tech-transfer and the protection of research results through patents and other Intellectual Property rights (IPR), such as copyright, trade secrets and database protection. Universities utilizing biobanks in this way must show due regard for the research value of samples and data, as they are custodians of the biobank's resources. EU Recommendation CM/Rec (2016) 6 lays down the principles of governance for obtaining, storage and use of biological materials along with interoperability of data for research purposes.

In Europe, the responsibilities of universities have been given certain navigational paths under EU Horizon 2020, which has established a set of rules concerning the exploitation and dissemination of project results, including their protection through IPR. Universities and other public research organizations are required, as beneficiaries, to take measures to implement the principles set out under the Code of Practice annexed to Commission Recommendation C (2008) 1329 of $10.4 .2008^{46}$ on the management of intellectual property in knowledge transfer activities. Under this Code, universities, while incentivizing innovation among their staff and students, are also required to seek protection of intellectual property, in line with the strategy and mission of the public research 
organization, with a view to maximizing socio-economic benefits such as the concept of open innovation. The Code also recognizes institutional ownership - as opposed to "professor's privilege" - as the default legal regime, although ownership arrangements may vary in case of collaborative research where the rights are allocated to the different parties on the basis of a contractual agreement concluded in advance. Hence university-linked biobanks, while promoting the use of research resources, must seek to clarify the allocation of ownership of foreground intellectual property generated within the framework of the biobank-based project. In addition, many European countries have adopted legislation which requires universities to pursue ownership of inventions made by their employees via the patent acts.

As a consequence of these initiatives, patent protection is often integral to research projects, including those that rely on biobanks. For this reason, it is vital to define the limits of patentable inventions. According to current European patent rules, and most importantly EC Directive 98/44/EC (Biotech Directive), inventions which satisfy the basic patentability criteria - i.e. novelty, inventive step and industrial applicability - shall be considered patentable even if they involve a product consisting of, or containing, biological material that previously existed in the natural world (Art. 3). Art. 5 makes it clear that this principle extends to human biological material provided that it has been isolated from the human body or otherwise produced by means of a technical process and (in relevant cases) that an industrial application of a sequence or a partial sequence of a gene has been disclosed in the patent application. Consequently, as soon as data derived from samples in a biobank can be used, for example, to link a certain genetic disorder to a disease, patent protection for the isolated genetic sequences or methods to generate modified human biological material becomes an option for researchers who can demonstrate that they have made an essential contribution to the invention. Defining the limits here is obviously extremely complicated and not something we shall pursue in the present discussion. In countries with legislation obliging universities to patent inventions, university researchers need to contact university patent experts if they so much as suspect that patent law could be applicable to their work. The university may decide to patent the invention and have the patent right transferred to them despite the interests of the inventor. Since the researcher's duty to act arises when patent 
protection is a possibility, the reach of patent law into university-based research goes beyond the limits of the legislation. It also follows from the special rules on university-based patents that universities themselves have an interest - and often indeed a legal duty - to secure patent protection whenever possible. In this way, the legal system has not only stacked the deck in favor of patent protection, but also generated a special interest for one of the stakeholders - universities - which may create tensions vis-à-vis other stakeholders (including employees).

Apart from patent law, other types of entitlement schemes may be relevant, including trade secrets, copyright and database rights. The last of these, underpinned by the EU's special rules on the protection of “databases" (Directive 96/9), may come into play and will often provide exclusivity for databases containing genomic information. But these systems of ownership of data/information may create tensions between stakeholders by identifying different groups as the beneficiaries of an ownership right. Database rights, for instance, may point towards either the university, the funder, or the researcher, as the beneficial owner. Normally, the various stakeholders will use agreements to parcel such rights in ways they consider valid.

The exploitation of publicly-funded research depends on proper management of intellectual property (in the broadest sense, encompassing inter alia inventions, software, databases and patents), and on the development of an entrepreneurial culture and associated skills within public research organizations which enhance interaction between the public and private sectors (rec C (2008) 1329). Where inventions arising out of biobank research are concerned, universities will often need to have special procedures in place to ensure both that potentially patentable inventions are reported and that genuinely patentable inventions are patented. Apart from patents, which always require target actions (applications) if they are to be obtained, various property rights may arise during the operation of biobanks. The administration of such rights requires special attention, strategy and tools, including special software solutions. The use of exclusive rights (such as database rights) must also be coordinated between the different actors. Otherwise the rights may prevent some actors from accessing and using the relevant database. Universities therefore need to have a system of coordination in place. 
Importantly, the strategy is not predefined by the existence of property rights. Even where the most exclusive right, i.e. a patent, is involved, universities may still pursue a strategy based on Openness. ${ }^{47}$ The default rule and ambition for publicly funded and tax-exempt universities that engage in the patenting of crucial technologies should perhaps be that patents are used as much as possible to deliver the greatest public benefit and/or to support researchers in bringing their work to fruition (assuming they should engage in patenting at all in the first place). For example, if key technologies are being developed from university biobank-driven research projects involving various institutions, and if there are compelling reasons to engage in patent protection, university guidelines should encourage and incentivize patent applications making broad reference to the researchers involved and the institutions as co-inventors. Any resulting patents could then be cross-licensed to other research institutions either freely or on very favorable conditions. ${ }^{48}$ Such guidelines could also stipulate that patents should be used to fund academic consortia dedicated to studying the relevant technologies, or they could be applied to ignite robust and beneficial competition for commercial applications of the technology by licensing the patents on non-exclusive terms to a variety of industry competitors, with the licensing fees then being invested into further academic research. ${ }^{49}$ As exemplified by current developments in gene editing technologies, such licensing regimes could also be used as interim tools to address currently unsolved ethical dilemmas posed by emerging technologies that are not being sufficiently regulated by existing regulations and state law. ${ }^{50}$ In that way, patents could be used as technology transfer and innovation policy tools rather than swords and shields.

Finally, it is important to bear in mind that (intellectual) property rights are just one of several issues that need to be addressed in the effort to enhance open science and data and sample sharing within the framework of public university biobanks. After all, it is not uncommon for university researchers to be happily unconcerned about, or simply ignore, IP rights. As we have detailed above, the competence and reliability of research partners, the trust that those partners are able to properly handle, utilize and further develop high quality data, the quality of the data 
they expect to receive in return, and the trust that recognition and acknowledgments are properly respected - these are often the most decisive factors when researchers decide to share (or not to do so). Considering the amount of human intervention, work, skills, dedication and investment that is often required to generate and store high quality biobank data, it comes as no surprise to learn that scientists are often reluctant to share their data. They become what <AUTHOR> calls "data huggers" 51 and might be understandably inclined to protect their data through IPRs. $^{52}$

Such data need to be differentiated from machine-generated data, and public universities will have to find a way to address data-hugging. IP guidelines alone will not suffice to manage it. A sustainable solution will require additional strategies, such as the development of recognized data quality standards in collaborative research projects, guidelines on acknowledgements and co-authorship, and enforceable guidelines on research ethics. If these issues are not addressed, the vision and aspiration of openness and smart data sharing might be crushed by harsh realities, secrecy-driven competition, and even aggressively enforced IP rights. If the goal is an academic environment where IP rights are used as shelters and ploughs, rather than swords, and if we want to encourage the notion that university research and biobanks collaborate and compete on their capacity to generate and analyze data, rather than on their ability to protect and own high-quality data, all the above issues will have to be addressed collectively.

\section{Conclusion: A framework for sustainability}

In this paper we have sought to identify an important challenge facing universities in relation to the maintenance and curation of a scientific resource which has in our view been neglected. Traditionally, universities have sought to develop practices which accumulate and improve the research resources they maintain, such as library collections and other types of archived research data. Biobank samples, however, have not received the level of attention and interest that other resources have garnered within universities. 
We suggest that universities should develop procedures which ensure that collections of human biological material stored within their facilities are sustainable when those collections are deemed to have special long-term value. The procedures should include the possibility of reassigning custodianship of the collections when their original custodian retires or moves to work elsewhere. They should also ensure the proper destruction of collections and data that are no longer needed.

We also suggest that universities develop both a short-term and a long-term perspective on the collection and storage of human tissue collections. Universities should recognize that the value of some biobanks transcends the interests of the university itself and the individual researcher and research group. Some collections may be of great value to the broader scientific community. It is important, however, that the rights and interests of the original custodian are also respected when the long-term sustainability of important collections is discussed.

It is essential for public institutions like universities to recognize that the effective use of tools such as intellectual property rights and knowledge transfer mechanisms must enable socio-economic research to proceed within a commitment to responsible research. ${ }^{53}$ Biomedical research, in particular, is contingent on the swift translation of research results to the benefit of patients. In this respect, university-linked biobanks must effectively engage in public-private partnership research which effectively enables such commitments to responsible medical research.

In concrete terms, we suggest that universities should be obliged to have institutional arrangements in place that enable them to identify special cases and decide whether unique collections should be preserved or destroyed. What these arrangements end up involving will depend on the individual universities themselves, and we would urge them to enter into dialogue with their research staff, as well as other relevant stakeholders (e.g. funding agencies and patients), to develop guidelines that the researchers are ready to commit to. Given that the majority 
of tissue collections housed in universities have been collected with public funding, we see this process as a matter of respecting the efficient use of public resources.

[TABLE 1: RECOMMENDATIONS ON SUSTAINABLE MANAGEMENT OF UNIVERSITY BIOBANKS]

\section{Acknowledgements}

The authors are grateful for the support of the "Global Genes - Local Concerns" project (see http://globalgenes.ku.dk/), under the umbrella of the University of Copenhagen's Excellence Programme for Interdisciplinary Research.

\section{References}

${ }^{1}$ Godin, B. and Gingras, Y. (2000). The place of universities in the system of knowledge production. Research Policy, 29(2), 273-278.

${ }^{2}$ Etzkowitz, H., Leydesdorff, L. (1997). Universities and the Global Knowledge Economy: A Triple Helix of University-Industry-Government Relations. London: Pinter. 
${ }^{3}$ Liu, L. G. (2001). The contribution of library collections to prestige of academic programs of universities: a quantitative analysis. Library Collections, Acquisitions, and Technical Services, 25(1), 4965.

${ }^{4}$ Lynch, C. A. (2003). Institutional Repositories: Essential Infrastructure For Scholarship in The Digital Age. portal: Libraries and the Academy, 3(2), 327-336.

${ }^{5}$ European Research Council (2017). Guidelines on Implementation of Open Access to Scientific Publications and Research Data in projects supported by the European Research Council under Horizon 2020. European Commission. https://erc.europa.eu/sites/default/files/document/file/ERC\%20Open\%20Access\%20guidelinesVersion\%201.1._10.04.2017.pdf. Accessed 20 Mar 2018.

${ }^{6}$ European Commission (2016). General for Research \& Innovation Guidelines on FAIR Data Management in Horizon 2020. EUROPEAN COMMISSION Directorate, H2020 Programme. http://ec.europa.eu/research/participants/data/ref/h2020/grants_manual/hi/oa_pilot/h2020-hi-oa-datamgt_en.pdf. Accessed 20 March 2018.

${ }^{7}$ NordForsk (2014). Joint Nordic Registers and Biobanks - A goldmine for health and welfare research. NordForsk Policy Papers, 5. Oslo: NordForsk.

${ }^{8}$ Zielhuis, G. A. (2012). Biobanking for epidemiology. Public Health, 126(3), 214-216.

${ }^{9}$ Keogh, B. (2011). European Biobanks Forge Cross-Border Ties. Journal of the National Cancer Institute, 103(19), 1429-1431.

${ }^{10}$ Gottweis, H. and Zatloukal, K. (2007). Biobank Governance: Trends and Perspectives. Pathobiology, 74(4), 206-211.

${ }^{11}$ Gottweis, H. and Lauss, G. (2010). Biobank governance in the post-genomic age. Personalized Medicine, 7(2), 187-195.

${ }^{12}$ Chalmers, D. et al. (2016). Has the biobank bubble burst? Withstanding the challenges for sustainable biobanking in the digital era. BMC Medical Ethics, 17(39). https://doi.org/10.1186/s12910-016-0124-2.

${ }^{13}$ Kaye, J., Gibbons, S.M.C., Heeney, C., Parker, M., and Smart, A. (2012) Governing Biobanks Understanding the Interplay Between Law and Practice. Oxford: Hart Publishng.

${ }^{14} \mathrm{H}$. Gottweis and G. Lauss, 'Biobank governance in the post-genomic age', Personalized Medicine, 7(2) (2010) 187-195.

${ }^{15}$ Scudellari, M. (2013). Biobank managers bemoan underuse of collected samples. Nature medicine, 19, 253. doi:10.1038/nm0313-253a.

${ }^{16}$ Scudellari, M. (2013). Biobank managers bemoan underuse of collected samples. Nature medicine, 19, 253. doi:10.1038/nm0313-253a.

${ }^{17}$ Eiberg, H., Mohr, J., Schmiegelow, K., Nielsen, L. S., Williamson, R. (1985). Linkage relationships of paraoxonase (PON) with other markers: indication of PON-cystic fibrosis synteny. Clinical Genetics, 28(4), 265-71. 
${ }^{18}$ Tsui, L. C., Buchwald, M., Barker, D., Braman, J. C., Knowlton, R., Schumm, J. W., Eiberg, H., Mohr, J., Kennedy, D., Plavsic, N., et al. (1985) Cystic fibrosis locus defined by a genetically linked polymorphic DNA marker. Science 230(4729), 1054-1057.

${ }^{19}$ Wainwright, B. J., Scambler, P. J., Schmidtke, J., Watson, E. A., Law, H. Y., Farrall, M., Cooke, H. J., Eiberg, H., Williamson, R. (1985) Localization of cystic fibrosis locus to human chromosome 7cenq22. Nature 318(6044), 384-5.

${ }^{20}$ Eiberg, H., Troelsen, J., Nielsen, M., Mikkelsen, A., Mengel-From, J., Kjaer, K.W., Hansen, L. (2008). Blue eye color in humans may be caused by a perfectly associated founder mutation in a regulatory element located within the HERC2 gene inhibiting OCA2 expression. Human Genetics, 123(2), 177-87. doi: 10.1007/s00439-007-0460-x. Epub 2008 Jan 3.

${ }^{21}$ Maretty, L., Jensen, J. M., Petersen, B., Sibbesen, J. A., Liu, S., Villesen, P., Skov, L., Belling, K., Theil Have, C., Izarzugaza, J. M. G., Grosjean, M., Bork-Jensen, J., Grove, J., Als, T. D., Huang, S., Chang, Y., Xu, R., Ye, W., Rao, J., Guo, X., Sun, J., Cao, H., Ye, C., van Beusekom J., Espeseth, T., Flindt, E., Friborg, R. M., Halager, A. E., Le Hellard, S., Hultman, C. M., Lescai, F., Li, S., Lund, O., Løngren, P., Mailund, T., Matey-Hernandez, M. L., Mors, O., Pedersen, C. N. S., Sicheritz-Pontén, T., Sullivan, P., Syed, A., Westergaard, D., Yadav, R., Li, N., Xu, X., Hansen, T., Krogh, A., Bolund, L., Sørensen, T. I. A., Pedersen, O., Gupta, R., Rasmussen, S., Besenbacher, S., Børglum, A. D., Wang, J., Eiberg, H., Kristiansen, K., Brunak, S., Schierup, M. H. (2017) Sequencing and de novo assembly of 150 genomes from Denmark as a population reference. Nature 548(7665), 87-91. doi: 10.1038/nature23264. Epub 2017 Jul 26.

${ }^{22}$ Mello, M. M. \& Wolf, L. E. (2010). The Havasupai Indian Tribe Case - Lessons for Research Involving Stored Biologic Samples. New England Journal of Medicine 363, 204-207. DOI: 10.1056/NEJMp1005203

${ }^{23}$ Hoeyer, K. (2004) The Emergence of an Entitlement Framework for Stored Tissue - Elements and Implications of an Escalating Conflict in Sweden. Science Studies 17(2), 63-82.

${ }^{24}$ The fieldwork involved following the work of geneticists and lab technicians in the laboratory in Denmark and following the work of researchers as they collected samples in rural Pakistan.

25 <AUTHOR>, forthcoming

${ }^{26}$ Hoeyer, K., Tupasela, A., \& Rasmussen, M. B. (2017). Ethics policies and ethics work in cross-national genetic research and data sharing: Flows, nonflows, and overflows. Science, Technology \& Human Values, 42(3), 381-404. DOI: 10.1177/0162243916674321

27 (<AUTHOR $>2017$

${ }^{28}$ The University of Copenhagen's rules for good scientific practice, September 2013, http://praksisudvalget.ku.dk/english/rules_guide/University_of_Copenhagen_s_rules_for_good_scientif ic practice.pdf. Retrieved 25 April 2018.

${ }^{29}$ The University of Copenhagen's policy on research data, July 2014, https://intranet.ku.dk/research/rcr/data-storage-andsharing/Documents/University\%20of\%20Copenhagen's\%20policy\%20on\%20research\%20data.pdf. Retrieved 25 April 2018. 
${ }^{30}$ Nowell, P., Hungerford, D. (1960). A minute chromosome in human chronic granulocytic leukemia. Science 132, 1497.

${ }^{31}$ Rowley, J. D. (1973) A new consistent chromosomal abnormality in chronic myelogenous leukaemia identified by quinacrine fluorescence and Giemsa staining. Nature 243(5405), 290-293.

${ }^{32}$ Stam, K., Heisterkamp, N., Reynolds, F. H. Jr, Groffen, J. (1987) Evidence that the phl gene encodes a 160,000-dalton phosphoprotein with associated kinase activity. Molecular and Cellular Biology. 7(5), 1955-1960.

${ }^{33}$ Druker, B. J., Tamura, S., Buchdunger, E., Ohno, S., Segal, G. M., Fanning, S., Zimmermann, J., Lydon, N. B. (1996) Effects of a selective inhibitor of the Abl tyrosine kinase on the growth of Bcr-Abl positive cells. Nature Medicine, 2(5), 561-6.

${ }^{34}$ Waller, C. F. (2014). Imatinib mesylate. Recent Results in Cancer Research, 201, 1-25.

${ }^{35}$ Academic Freedom at the University of Copenhagen, September 2015, https://intranet.ku.dk/research/rcr/rules-norms-andinstitutions/Documents/Forskningsfrihed\%20UCPH\%20all\%20EN.final15.pdf. Retrieved 25 April 2018 .

${ }^{36}$ Freedman, L. P., Cockburn, I. M. \& Simcoe, T. S. (2015) The Economics of Reproducibility in Preclinical Research. PLOS Biology, 13(6), 1-9.

${ }^{37}$ See also <AUTHOR> forthcoming

${ }^{38}$ Douglas C., van El, C., Radstake, M., van Teeffelen, S. and Cornel, M. C. (2012). The Politics of Representation in the Governance of Emergent 'Secondary Use' Biobanks: The Case of Dried Blood Spot Cards in the Netherlands. Studies in Ethics, Law, and Technology, 6(1). DOI: https://doi.org/10.1515/1941-6008.1178.

${ }^{39}$ Cambon-Thomsen, A. (2004). The social and ethical issues of post-genomic human biobanks. Nature Review Genetics, 5, 866-873. doi:10.1038/nrg1473.

${ }^{40}$ Holub P., Swertz M., Reihs R., van Enckevort, D., Müller H., and Litton, JE. (2016). BBMRI-ERIC Directory: 515 Biobanks with Over 60 Million Biological Samples. Biopreservation and Biobanking, 14(6), 559-562. https://doi.org/10.1089/bio.2016.0088

41 Wilkinson, M. D. et al. (2016). The FAIR Guiding Principles for scientific data management and stewardship. Sci. Data 3:160018 doi: 10.1038/sdata.2016.18.

42 Erslev, T. (2017). A brain worth keeping? Waste, value and time in contemporary brain banking. Studies in History and Philosophy of Science Part C: Studies in History and Philosophy of Biological and Biomedical Sciences. https://doi.org/10.1016/j.shpsc.2017.12.002.

${ }^{43}$ Willensky, J. (2006). The Access Principle: The Case for Open Access to Research and Scholarship. Cambridge, Massachussetts: MIT Press.

${ }^{44}$ Wilkinson, M. D. et al. (2016). The FAIR Guiding Principles for scientific data management and stewardship. Sci. Data 3:160018 doi: 10.1038/sdata.2016.18.

45 The BBMRI guidelines currently being developed might serve as an initial source of inspiration: http://www.bbmri-eric.eu/wp-content/uploads/2017/03/BBMRI-

ERIC_FAQs_on_the_GDPR_V2.0.pdf. 
${ }^{46}$ Commission Recommendation on the management of intellectual property in knowledge transfer activities and Code of Practice for universities and other public research organisations, C (2008)1329. http://ec.europa.eu/invest-in-research/pdf/ip_recommendation_en.pdf. Accessed 20 Mar 2018.

${ }^{47}$ Verlinden, M., Minssen, T. \& Huys, I. (2016), Reconciling IPRs and openness in biobanking. European Intellectual Property Review, 38(1), 1-4.

${ }^{48}$ Sherkow, J. S. (2016) Pursuit of profit poisons collaboration. Nature, 532 , 172-173.

${ }^{49}$ Ibid., Sherkow, J. S. (2017) Patent protection for CRISPR: An ELSI review. Journal of Law and the Biosciences, 4(3), 565-576.. doi:10.1093/jlb/lsx036 (2017)

50 Guerrini, C. J. (2017). The rise of the ethical license, Nature Biotechnology 35, 22-24. doi:10.1038/nbt.3756.

$51<$ AUTHOR> 2017

${ }^{52}$ For a discussion of "biohoarding", see also Catchpoole, D. (2016). 'Biohoarding': Treasures Not Seen, Stories Not Told. Journal of Health Services Research \& Policy 21(2), 140-142.

$53<$ AUTHOR> 2014 